\title{
Eingreifende Denkerinnen
}

\author{
Weibliche Intellektuelle im 20. und 21. Jahrhundert \\ Hrsg. v. Ingrid Gilcher-Holtey
}

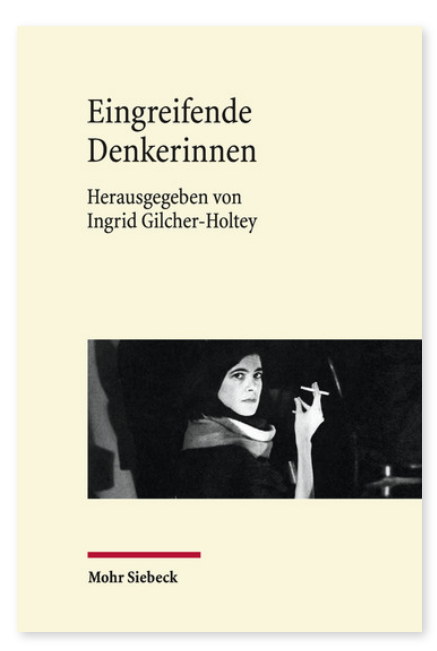

2015. VI, 251 Seiten.

ISBN 978-3-16-153824-7

DOI 10.1628/978-3-16-153824-7

eBook PDF $64,00 €$

ISBN 978-3-16-153650-2

Festeinband $64,00 €$
Wer ein Intellektueller ist, ist umstritten. In einem aber gleichen sich die Studien zur Geschichte der Intellektuellen: Sie blenden Frauen aus. Dieser Band gibt Frauen ein Forum, die als Kulturproduzentinnen im 20. und 21. Jahrhundert mit öffentlichen Stellungnahmen in die politische Arena eingegriffen und damit die Rolle der Intellektuellen wahrgenommen haben. Was forderte ihre Einmischungen heraus? Wie griffen sie ein? Orientierten sie sich an männlichen Vorbildern? Oder begründeten sie eigene Formen gesellschaftspolitischen Engagements? Die Autoren der Studien untersuchen Interventionsstrategien weiblicher Intellektueller in Konstellationsanalysen und entfalten das facettenreiche Rollenrepertoire und die Waffen der Kritik von 14 »Eingreifenden Denkerinnen«: Käthe Kollwitz, Erika Mann, Margarete Buber-Neumann, Hannah Arendt, Simone de Beauvoir, Rita Levi Montalcini, Rossana Rossanda, Carla Lonzi, Susan Sontag, Yoko Ono, Jeanne Hersch, Elfriede Jelinek, Judith Butler und Naomi Klein. Als widerständige Zeitdiagnostikerinnen stellten sie, sich einmischend in die Politik, etablierte Weltanschauungen, Wahrnehmungsschemata, Werte und Einstellungen in Frage, um einen 'neuen" 'anderen' Blick auf die Gesellschaft freizulegen. Sie ergriffen das Wort in Verteidigung der Rechte anderer. Sie artikulierten Unbehagen, klagten Missstände an, deckten Diskriminierungen und Menschenrechtsverletzungen auf. Sie provozierten durch Widerspruch, Dissens, Eigensinn. Das gesellschaftspolitische Engagement Eingreifender Denkerinnen überdauerte, wie die Studien zeigen, den vermeintlichen »Tod des intellektuellen« (Lyotard) in den 1980er Jahren. Es zeigt vielmehr Kontinuitäten und Wandel in der Wahrnehmung der Rolle der Intellektuellen im 20. und 21. Jahrhundert auf.

\section{Inhaltsübersicht}

Ingrid Gilcher-Holtey: Prolog: Eingreifende Denkerinnen - Steffen Bruendel: Käthe Kollwitz: Macht und Ohnmacht der Kunst Kristina Schulz: Erika Mann im Schweizer Exil : Die »Pfeffermüllerin« und das intellektuelle Unternehmen - Brigitte Studer: Margarete Buber-Neumann: Die Erfahrung totalitärer Systeme als symbolisches Kapital - Eva Oberloskamp: Simone de Beauvoir: Die Verteidigung Djamila Boupachas - Katrin Stoll: Hannah Arendts Lehren aus dem Eichmann-Prozess: Denken und Urteilen - Marica Tolomelli: Rita Levi Montalcini, Rossana Rossanda, Carla Lonzi: Drei Modelle des Engagements - Silja Behre: Simone de Beauvoir und das Russel-Tribunal - Henning Marmulla: Yoko Ono und die Macht der Kunst - Stephan Isernhagen: Susan Sontag und der Vietnamkrieg: Die empfindsame Intellektuelle - Dorothee Liehr: Jeanne Herschs Intervention in den »Fall Kopp«: Vom Skandal zur Affäre - Franziska Schößler: Elfriede Jelinek: Aporien der Kritik und der Kampf um Rederechte - Bettina Brandt: Judith Butler: Verteidigung der Palästinenser - Ingrid Gilcher-Holtey: Naomi Klein \& Co: Intellektuelle in der Globalisierungskritischen Bewegung - Agnes Heller: Epilog: Hannah Arendts Platz im spätmodernen Denken

Ingrid Gilcher-Holtey ist Professorin für Allgemeine Geschichte unter besonderer Berücksichtigung der Zeitgeschichte an der Universität Bielefeld und assoziiertes Mitglied des Centre de Sociologie Européenne (CSE/EHESS-Paris).

Jetzt bestellen:

https://mohrsiebeck.com/buch/eingreifende-denkerinnen-9783161538247?no_cache=1

order@mohrsiebeck.com

Telefon: +49 (0)7071-923-17

Telefax: +49 (0)7071-51104 